These experiments show that regeneration in a mammalian nerve can be completely inhibited by an environmental temperature near freezing point for at least thirty-five days, although by that time all fibres show advanced degenerative changes: at environmental temperatures near $20^{\circ} \mathrm{C}$., regeneration proceeds rapidly. It is not yet known what temperature may be optimal for this process.

It is perhaps relevant that Barcroft and Edholm ${ }^{6}$ have recorded temperatures in the deep muscles of the limbs of man and have shown that these may be as much as $6^{\circ} \mathrm{C}$. below rectal temperature after exposure to cool air, and as much as $17-18^{\circ} \mathrm{C}$. below rectal temperature after exposure to cold water. Taken in conjunction with the present findings, this suggests that environmental temperatures may be of considerable general significance in affecting the rate of recovery after nerve injury.

St. Mary's Hospital Medical School,

$$
\text { H. J. Gamble }
$$

London, W.2. April 3.

${ }^{1}$ Lubinska, L., and Olekiewicz, M., Acta Biol. Exp. Varsovie, 15, $125(1950)$.

${ }^{2}$ Gamble H. J., Goldby, F., and Smith, G. M. R., Nature, 179, 527 (1957)

s Dieneka, D., Folia Neurobiol., 2, 13 (1908).

- Muggins, C., Blocksom. B. H., and Norman, W. J.. Amer. J. Physiol., $115,395(1936)$

'Vizozo, A. D., and Young, J. Z., J. Anat., Lond., 82, 110 (1948).

'Barcroft, H., and Edholm, O. G., J. Physiol., 104, 366 (1946).

\section{Lampbrush Chromosomes in Insects}

THE lampbrush chromosomes have been described in the male germ-cells of Orthoptera ${ }^{1}$ and more widely in vertebrate eggs. Recently, in this laboratory also, these have been observed in the male germ-cells of not only the short-horned grasshoppers but also the gryllids. Our preparations were made after excellent fixation in Sanfelice and Bouin-Allen fluids, and these were stained with 0.5 per cent iron hæmatoxylin.

Apart from their morphology, the appearance of lampbrush chromosomes, in these insects, is correlated with the growth of the auxocyte. The premeiotic resting cell enters the leptotene stage directly without any significant growth in size. During pachytene, the cell enters the growth period and simultaneously the autosomal bivalents assume the lampbrush form, which persists until late diakinesis, when the cell has grown to its full size. In the normal mitotic cycle, the growth of the cell, which usually takes place in the resting period, is accompanied by practically the complete depolymerization of the nucleic acids, with the despiralization of the chromonemata. The lampbrush appearance of the chromosomes in the germcells of these insects may be physiologically correlated. with the cellular growth and depolymerization, unaccompanied, however, by the complete suppression of the progressive meiotic changes in the chromosomes. The same is, perhaps, true of the oocytes.

The diffused or confused stage of Heteroptera, which usually interrupts the diplotene stage at its very beginning, may be regarded as representing a still further step. Similarly, the complete 'resting' condition of the diffused nucleus in most heteropterans represents the growth of the cell with complete depolymerization of the nucleic acids, unaccompanied by the complete suppression of the progressive meiotic changes in the autosomes. Consequently, as they reappear out of the confused stage, they have already undergone a good deal of contraction, with the terminalization of most of their chiasmata. The representation of the diffused lampbrush elements in some pyrrhocorid bugs studied by us points to the common nature of growth both in Heteroptera and Orthoptera, which, in the former, is accompanied by the more or less complete depolymerization of the nucleic acids and, in the latter, by its incomplete depolymerization and consequently the lampbrush appearance of the chromosomes. The approach to a state of complete depolymerization of the nucleic acids and very slight growth of the auxocyte at the early diplotene in the grasshopper, Pcecilocerus pictus, result in a comparatively rare occurrence of the lampbrush fibres in that species.

G. P. SHARMA
RAM PARSHAD
Department of Zoology, Panjab University,
Hoshiarpur, India. March 11.
'Hsu, T. C.., J. Genet., 48, 311 (1948. Ris, H., Biol. Bull., 89, 242
(1945). Srivastava, M. D. L., J. Genet., 52, $480(1954) ;$ La Cellule,
52, 271 (1956).

\section{New s-Triazine Herbicides}

In the course of investigations on $s$-triazines, we have discovered a new synthesis of 2-alkoxy- and 2-alkylthio-4,6-dichloro-s-triazines. These substances can be obtained by the reaction of an alcohol or a thiol with cyanuric chloride and 2,6 $x$ collidine as the acid acceptor. The yield was approximately 80-90 per cent. In a further systematic investigation, we found that in these compounds the chlorine atom can be specifically substituted in good yield by an alkylamino, alkyloxy or alkylthio group.

Compounds with the structure :

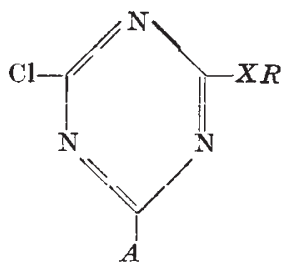

in which $X$ is $-\mathrm{NH}-,-\mathrm{O}--$ or $--\mathrm{S}-, R$ is an alkyl group and $A$ is chlorine or $Y R(Y$ may be only $-\mathrm{O}$ - or - $\mathrm{S}-$ ), exhibited strong phytotoxic activity on many plant species (patents applied for).

Illustrative for this action is Fig. 1, which shows the results of spraying chickweed, beet, tomato, oats and beans (from left to right) with 1 per cent solution of 2-pentoxy-4,6-dichloro-s-triazine ( $T R$ 110) in a quantity corresponding to $10 \mathrm{kgm}$. per hectare. 2-n-Butoxy-4,6-dichloro-s-triazine $(T R 14)$ and 2-nbutylthio-4,6-dichloro-s-triazine ( $T R$ 35) gave similar results. Fig. 2 shows a control series of pots.

By varying the alkyl group $R$, we found that the triazines with a side-chain of three to six carbon

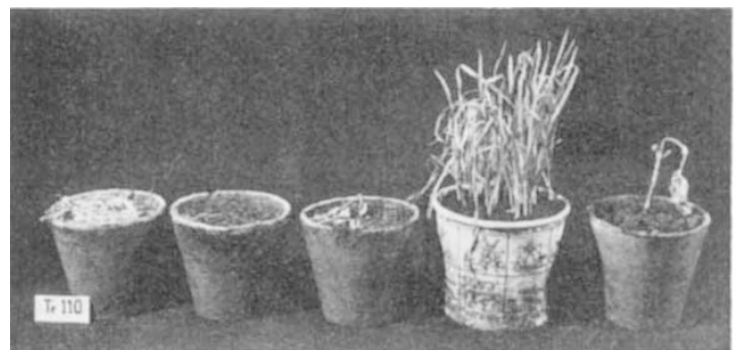

Fig. 1 